http://jmscr.igmpublication.org/home/

ISSN (e)-2347-176x ISSN (p) 2455-0450

crossref DOI: https://dx.doi.org/10.18535/jmscr/v8i7.22

Journal Of Medical Science And Clinical Research

\title{
Erectile Dysfunction and Testosterone Deficiency in Young Men
}

Authors

\author{
Dr Satyanarayana Reddy Alla, MD ${ }^{1 *}$, FECSM., Dr Ambujam G. MS. ${ }^{2}$ \\ ${ }^{1}$ Consultant in Sexual Medicine, Leo Institute of Sexual Medicine, Hyderabad \\ ${ }^{2}$ Professor in General Surgery, VMMC\&H, VMRF (DU) \\ *Corresponding Author \\ Dr Allasatyanarayana Reddy
}

Leo Institute of Sexual Medicine, Rajbhavan Road, Somajiguda, Hydertabad, India 500082

Abstract
Erectile Dysfunction (ED) is a common sexual problem, the prevalence increasing with age; severe ED
seen in 5\% of men at 40, tripling to $15 \%$ in men at 70 years of age. The prevalence rates of ED in young
men in 20-40 years age group varies from $1.7 \%$ to $13 \%$ in various studies. Low testosterone is a well
known but uncommon cause of ED.
This study aims at identifying hypogonadism in young men with ED. This is a retrospective clinic based
study from South India done on young men of $20-40$ years. One group of 142 men with Premature
Ejaculation (PME), no ED; and another group of 269 men with ED with or without PME,
demographically similar, attended the clinic during the same time were compared.
$3 \%$ of men in PME group and $17 \%$ of men in ED group had total testosterone less than 240 ng/dl. $22 \%$
of men in PME group and $49 \%$ of men in ED group had total testosterone less than 360 ng/dl. The mean
Total Testosterone (TT) value in PME group was 520 and the mean TT in ED group was $406 . n g / d l$. All of
these are statistically significant. Hence it can be inferred that, even in young men, testosterone
deficiency is not a rare cause, but a significant cause of ED.
Keywords: Erectile Dysfunction; Testosterone: Hypogonadism.

\section{Introduction}

The prevalence of erectile dysfunction is age dependant. $5 \%$ of men have severe ED and and $40 \%$ of men have some erection problem at 40 years of age. At seventy years of age, severe ED tripled to $15 \%$ and $70 \%$ of men had some erection problem at 70 years of age ${ }^{(1)}$. This classical prevalence data of ED by Massachusetts Male Aging Study (MMAS) study done in USA a quarter century ago may not be universal, may not hold good today.

In a community based study done in South India, $13 \%$ of men in $18-25$ years age group, $8.6 \%$ of men in 26-30 years age group and 9.9\% of men in $30-40$ years age group were having $\mathrm{ED}^{(2)}$. In another study done on military recruits in Switzerland in 18-26 years age group, $30 \%$ had some degree of $\mathrm{ED}^{(3)}$.

Traditionally, ED in young men is thought to be psychogenic in $85 \%$ and organic in $15 \%$ only. Researchers showed that, the ratio of psychogenic causes of ED vs organic causes of ED in young men were $85.2 \%$ vs $14.8 \%, 40.7 \%$ vs $59.3 \%$, $13 \%$ vs $87 \%$ in different studies ${ }^{(4,5)}$. There is a huge variation in different studies. 
Testosterone and erections: erections are androgen dependant, as evidenced by castrated men having poor sexual function and exogenous supplementation in these men restores sexual function ${ }^{(6)}$. However, the level of hypogonadism required to induce $\mathrm{ED}$ is debatable ${ }^{(7)}$. It is thought that normal testosterone level is not required for normal erections to occur, and additional amounts of testosterone do not further increase erection function. In severely hypogonadal men, replacement of testosterone restores sexual function in only $40-60 \%$ of the patients ${ }^{(14)}$.EMAS demonstrated that there was a testosterone thresh hold for the relationship between total testosterone and ED. Total testosterone (TT) was associated with worse sexual functioning at concentration of TT 240ng/dl or less ${ }^{(8)}$. But it was observed that, the ED correlates well with free testosterone and bio available testosterone, than total testosterone. There is an age dependant decrease in testosterone production. Total testosterone decreases by $1.6 \%$, albumin. Sex Hormone Binding Globulin (SHBG) increases by $1.3 \%$ per year, resulting in a decrease in free testosterone by $2.8 \%$ and albumin bound testosterone by $2.5 \%$ per year.

Testosterone deficiency is not a common cause of $\mathrm{ED}$, accounting for only about $6 \%$ of cases in general. In young men with ED, 2-3\% have TT $<200 ; 12 \%$ have TT $<300 ; 18 \%$ haveTT $<350$ (ESSM manual). In another study, only $4 \%$ of men younger than 50 years with ED were found to have low testosterone. However, it is unclear, whether this was a contributory factor in this population $^{(10)}$.

But in clinical practice, even in young men with $\mathrm{ED}$, it is observed that low testosterone is more common than what is quoted in literature. To have a clinical correlation of ED and hypogonadism in young men, this study was undertaken.

\section{Aim of the Study}

To assess testosterone deficiency in young men with erectile dysfunction.

\section{Material and Methods}

This is a retrospective study done on young men, who attended our private clinic during the calendar years 2014, 2015. Men in the age group of 20-40 years, with chief complaint of erection failures and/or quick ejaculation in partnered sex are the subjects of analysis. Men who got clinical examination, investigated and treated, followed for a minimum of three months are only included. Men who are on a hormonal intervention for a sex problem or for infertility in the past three months are excluded from the study.

All investigations were done fasting before $10 \mathrm{am}$ (though TT estimation has to be done in the morning hours and fasting is not necessary, it is done fasting in all men as a convenience and standard for all other tests and for diabetics). TT estimation is done by the same clinical laboratory, by the same technique, measured in $\mathrm{ng} / \mathrm{dl}$; the quoted normal range being 241-827 ng/dl.

Information extracted from their records is tabulated as-age; marital status-married, unmarried, others; principle presenting sexual problem, duration of the problem, consistent or inconsistent, associated with distress or not; associated sexual problems; co morbidities; morning total testosterone; other hormones; other investigations; his psychological traits; partner's sexual problems; interpersonal relations with the partner; any other points of specific interest.

The men are divided into three groups

Group 1: men with PME alone without ED

Group 2: men with erection problem with or without PME, their erection failures fulfilling all the criteria laid down by DSM4 TR to be diagnosed as ED (persistent erection failures lasting for a minimum of six months; occurring in at least $75 \%$ of sex encounters)

Group 3: men with erection failures, their erection failures bothering them or their partners; but the erection failures do not fulfil all the criteria laid down by DSM4 TR to diagnose ED. 


\section{JMSCR Vol||08||Issue ||07||Page 112-116||July}

\section{Results}

Total men in the study: 601

Group 1: men with PME without erection failures-142
Group 2: men with ED with or without other sexual problems--269

Group 3: men with erection failures, but not qualifying for diagnosis of ED--190

Table 1: Total testosterone values in $\mathrm{ng} / \mathrm{dl}$

\begin{tabular}{|l|c|c|c|c|c|}
\hline & Number & TT<240 & TT<360 & TT<450 & TT $>821$ \\
\hline Group 1 & 142 & $4(3 \%)$ & $31(22 \%)$ & $60(42 \%)$ & $6(4 \%)$ \\
\hline Group 2 & 269 & $48(17 \%)$ & $132(49 \%)$ & $176(62 \%)$ & $5(2 \%)$ \\
\hline Group 3 & 190 & $13(7 \%)$ & $57(30 \%)$ & $91(48 \%)$ & $8(4 \%)$ \\
\hline
\end{tabular}

$17 \%$ of young men with ED had testosterone deficiency, i.e. less than $240 \mathrm{ng} / \mathrm{dl}$. If $360 \mathrm{ng} / \mathrm{dl}$ is taken as low normal, then $49 \%$ had testosterone deficiency. Compared to the ED group, only $3 \%$ had TT value less than 240 and $22 \%$ had TT value less than 360ng/dl in PME group. This is statistically significant. In group 3-7\% had TT less than 240 and $30 \%$ had TT less than $360 \mathrm{ng} / \mathrm{dl}$.

Bar diagram of total testosterone values in percentages

Percentage of young men in various blocks of total testosterone values

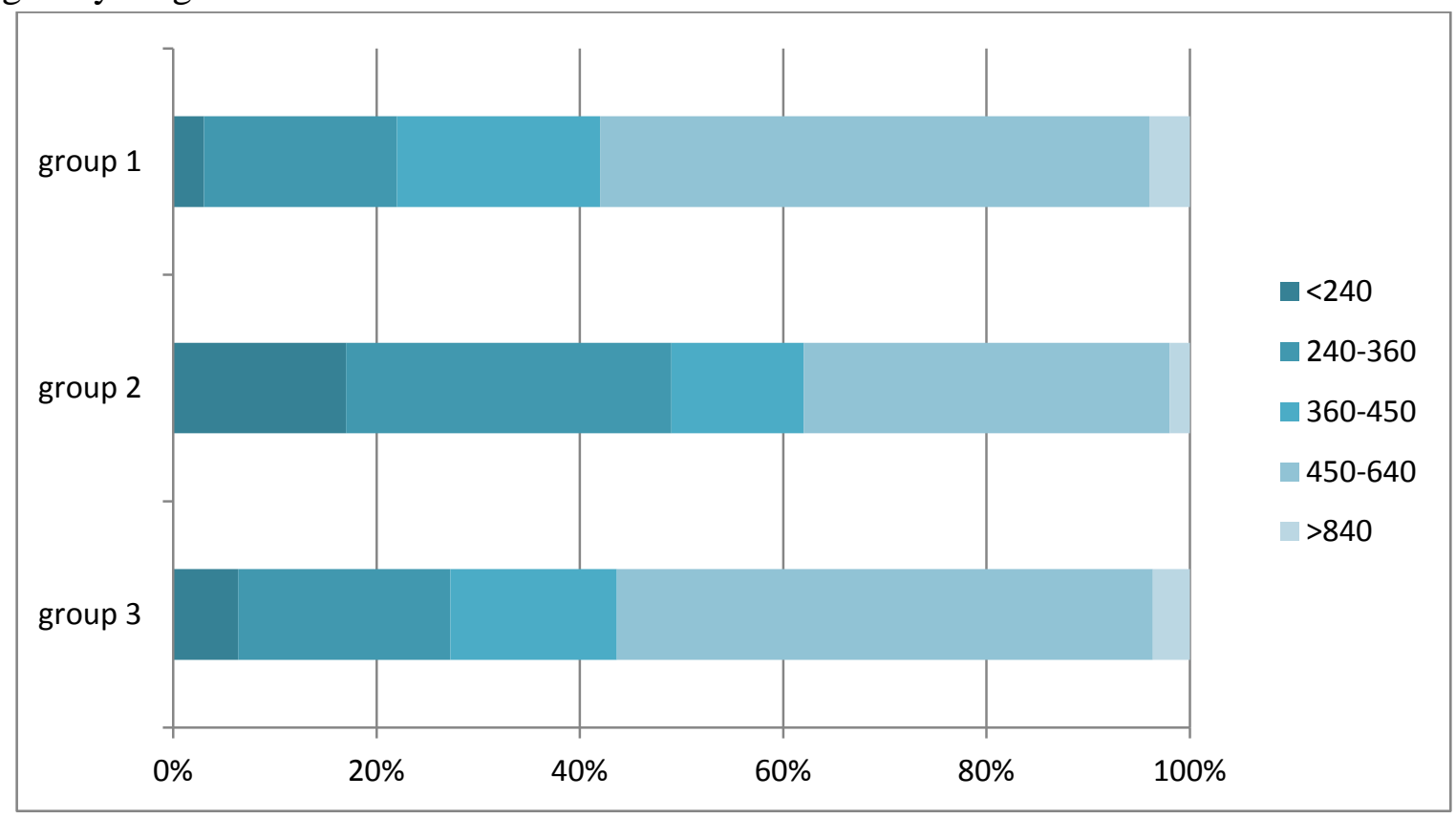

\begin{tabular}{|l|c|c|c|c|}
\hline & Group 1 & Group 2 & Independent sample t test statistical value & P value \\
\hline Mean TT & $406+-193.25$ & $520+-168.50$ & 9.93 & $<0.001$ \\
\hline range & 107,880 & 196,870 & & \\
\hline
\end{tabular}

Mean testosterone in PME group is $520 \mathrm{ng} / \mathrm{dl}^{*}$ Mean testosterone in ED group is $406 \mathrm{ng} / \mathrm{dl} *$. *The mean total testosterone values in men are statistically significant differing between the two groups ( $\mathrm{P}$ value $<0.001$ ), also mean TT value is114 units higher in group 2
Sex problems associated with ED, in the 269 young men with ED are

Premature ejaculation-86

Sexual orientation problems-homosexuality, bisexuality, asexuality- 8

Delayed ejaculation-3

Loss of libido-1

Bondage, Discipline, Sadism, Masochism (BDSM)-1 
The comorbidities observed in 269 young men with ED are

Diabetes Mellitus-32 (12\%)

Hypertension- 30 (11\%)

Dyslipidemia-46 ( 17\%)

Psychiatric illness-19 (7\%)

Phimosis 16 (6\%)

Total -one or more comorbidities 94 (35\%)

Other hormonal disturbances are-

Primary hypogonadism 5

Severe hyperprolactinemia 2; mild 14

Pituitary tumour 1

TSH high 13

\section{Discussion}

In a non institutional study in Chinese men aged $17-88$ years, at 20 years of age, $1.7 \%$ of men had severe ED, $6.5 \%$ of men had moderate ED. The total testosterone level was almost same in men with $\mathrm{ED}$ and in men without $\mathrm{ED}^{(11)}$.In the primary care services of NHS in England, in diabetic men with ED, in all groups together, 19\% had total testosterone less than $240 \mathrm{ng} / \mathrm{dl}$ and $21 \%$ had TT levels of $240-360 \mathrm{ng} / \mathrm{dl}^{(13)}$.In non institutional civilian population study in USA, in men more than 20 years of age, $18.4 \%$ had ED; the crude prevalence in diabetic men was more than $50 \%$; in 20-39 years age group, $5.1 \%$ of men had $\mathrm{ED}^{(15)}$.

International consultation committee for sexual medicine (Lisbon 2018) recommended a total testosterone value of $350 \mathrm{ng} / \mathrm{dl}$ may be used as a limit for testosterone deficiency in clinical practice. The symptoms of testosterone deficiency correspond more closely to free testosterone than total testosterone. The diagnosis of testosterone deficiency can be made on low free testosterone or low bioavailable testosterone, even if TT is normal $^{(9)}$.

In the present study, in young men less than 40 years of age with $\mathrm{ED}, 17 \%$ had total testosterone less than $240 \mathrm{ng} / \mathrm{dl}$, compared to only $3 \%$ of men with PME without ED had TT<240 ng/dl. In men with erection problems, but not qualifying for a diagnosis of ED, $7 \%$ of men had TT less than 240 $\mathrm{ng} / \mathrm{dl}$. If this last group of men were followed for some months, they may be classified as ED by definition. This explains the value being higher than seen in PME group and significantly lower than in ED group. Further $32 \%$ of men with ED had TT values between 240-360 ng/dl; where as $19 \%$ of men with PME had TT values between 240-360 ng/dl. $22 \%$ of men in PME group and $49 \%$ of men in ED group had TT values less than $360 \mathrm{n} / \mathrm{dl}$. The mean TT value in PME men is 520 $\mathrm{ng} / \mathrm{dl}$ and in the ED group the mean TT value is 406, which is statistically significant. When compared with other studies, in this study of young men with ED, the testosterone deficiency is more.

This is a study done in an exclusive sexual medicine clinic, not in the community, not in the primary care set up. This is not a representative sample of young men, as around half of the clients utilising the services of the clinic were information technology professionals. In this study, only a single estimation of testosterone is done; not confirmed by a second test; free testosterone, bio available testosterone, SHBG were not estimated.

\section{Conclusions}

Testosterone deficiency is not uncommon in young men with ED. Large scale controlled, comprehensive studies are needed to ascertain the prevalence of ED and the levels of total, free, bio available testosterone in young men with ED.

\section{Conflict of interest: Nil}

\section{References}

1. Feldman HA et al. Impotence and its medical and psychosocial correlates: results of the Massachusetts male aging study. J Urol 1994; 151: 54-61.

2. Sathyanarayana Rao T S, Darshan M S, Tandon A. An epidemiological study of sexual disorders in south Indian rural population. Indian J Psychiatry 2015; 57:150-7 
3. Journal of Adolescent Health, Volume 51, Issue 1, 25 - 31

4. Int. J Urol 2004;Tl:525-529

5. Int J Impot Res 1993; 5:97-103

6. Benkert O, Witt W, Adam W, Leitz A. Effects of testosterone undecanoate on sexual potency and the hypothalamicpituitary-gonadal axis of impotent males. Arch Sex Behav. 1979;8:471-480.

7. Testosterone supplementation for hypogonadal impotence: assessment of biochemical measures and therapeutic outcomes. J Urol. 1997; 157:849854.

8. Buena F, Swerdloff R, Steiner BS, et al. Sexual function does not change when serum testosterone levels are pharmacologically varied within the normal male range. FertilSteril. 1993;59: 1118-1123.

9. Morgentaler A, Traish A, Hackett G, et al. Diagnosis and Treatment of Testosterone Deficiency: Updated Recommendations From the Lisbon 2018 International Consultation for Sexual Medicine. Sex Med Rev 2019;7:636-649.

10. Urol Int 2014;92:1-6 DOI: $10.1159 / 000354931$

11. Liao M, Huang X, Gao Y, Tan A, Lu Z, et al. (2012) Testosterone Is Associated with Erectile Dysfunction: A Cross-Sectional Study in Chinese Men. PLoS ONE 7(6): e39234. doi:10.1371/journal.pone.0039234

12. O'Connor DB, Lee DM, Corona G, Forti G, Tajar A, et al. (2011) The Relationships between Sex Hormones and Sexual Function in Middle-Aged and Older European Men. J Clin Endocrinol Metab 96: E1577-E1587.

13. David J, Edwards D, Wright P (2017) REVITALISE audit: Erectile dysfunction and testosterone review in primary care. Diabetes \& Primary Care 19: 67-72.
14. Jain P, Rademaker AW, McVary KT. Testosterone supplementation for erectile dysfunction: results of a meta-analysis. $\mathbf{J}$ Urol 2000; 164: 371-375.

15. The American Journal of Medicine (2007) $120,151-157$. 